\title{
Conjugation of $A$ and B Blood Group Structures to Silica Microparticles for the Detection of Antigen- Specific B Cells
}

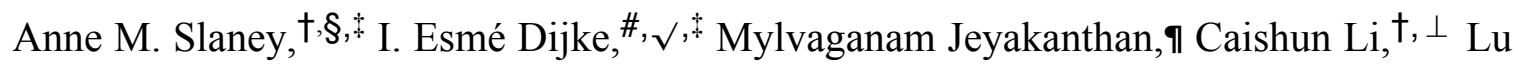
Zou, ${ }^{\dagger, \perp}$ Patrice Plaza-Alexander, ${ }^{\dagger, \perp}$ Peter J. Meloncelli, ${ }^{\dagger}, \perp$ Jeremy A. Bau, ${ }^{\dagger, \S}$ Lenka L. Allan, ${ }^{*}$ Todd L. Lowary, ${ }^{\dagger, \perp}$ Lori J. West, ${ }^{\#, q}, \diamond, \sqrt{ }$ Christopher W. Cairo, ${ }^{\dagger, \perp}$ Jillian M. Buriak $^{*},+, £$

$\dagger^{\dagger}$ Department of Chemistry, ${ }^{\perp}$ Alberta Glycomics Centre, \#Department of Pediatrics, ๆ Department of Surgery, $\diamond$ Department of Medical Microbiology/Immunology, $\sqrt{ }$ Alberta Transplant Institute, University of Alberta, Edmonton, AB, Canada, T6G 2G2

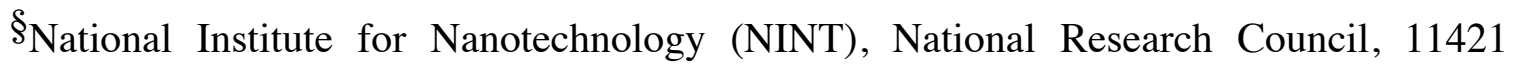
Saskatchewan Drive, Edmonton, AB, Canada, T6G 2M9

${ }^{\ddagger}$ Pathology and Laboratory Medicine, Faculty of Medicine, Vancouver General Hospital, JP Pavilion North, University of British Columbia, 855 West 12the Ave, Vancouver, BC, V5Z 1M9

†Contributed equally

*To whom correspondence should be addressed: jburiak@ualberta.ca 


\section{TABLE OF CONTENTS}

Background information regarding level of dye incorporation in silica microparticles

Figure S1. Detection of fluorescence of microparticles by flow cytometry with varying amounts of incorporated i) AF647 and ii) AF488 dye.

Table 1. Quantification of functionalizable amine groups, as per the section in the experimental section of the main text, entitled, Surface functionalization of microparticles with APTMS.

Figure S2. Detection of non-specific antibody binding to antigenfunctionalized microparticles.

Figure S3. Analysis of peak MFIs of cells bound to A-antigenfunctionalized microparticles.

Figure S4. Cells bound to A-antigen-functionalized microparticles have a high level of $\mathrm{B}$ cell receptor (BCR) expression. 


\section{Background information regarding level of dye incorporation in silica}

microparticles. In order to characterize the incorporated dye, excitation and emission spectra for the microparticles were obtained. The absorption maximum and emission maximum reported for AF647 dye by the manufacturer are $650 \mathrm{~nm}$ and $668 \mathrm{~nm}$ respectively. The covalently-bound AF647 excitation maximum in the microparticles was about $653 \mathrm{~nm}$, and the emission maximum was $665 \mathrm{~nm}$. Microparticles were easily detected by flow cytometry, but for possible future in vivo studies, much greater fluorescence intensity would be necessary. The quantity of fluorophore added was increased and, as demonstrated below, no quenching of the dye was noted within the amounts of dye used; appropriate dye concentrations for further studies in vivo could be identified. For flow cytometry detection, $500 \mu \mathrm{g}$ AF647 per gram of microparticles was determined optimal since the fluorescence is highest and stays within detection limits of our instrument at this concentration. In contrast, $800 \mu \mathrm{g}$ AF488 per gram of microparticles optimizes detection by our flow cytometry instrument.
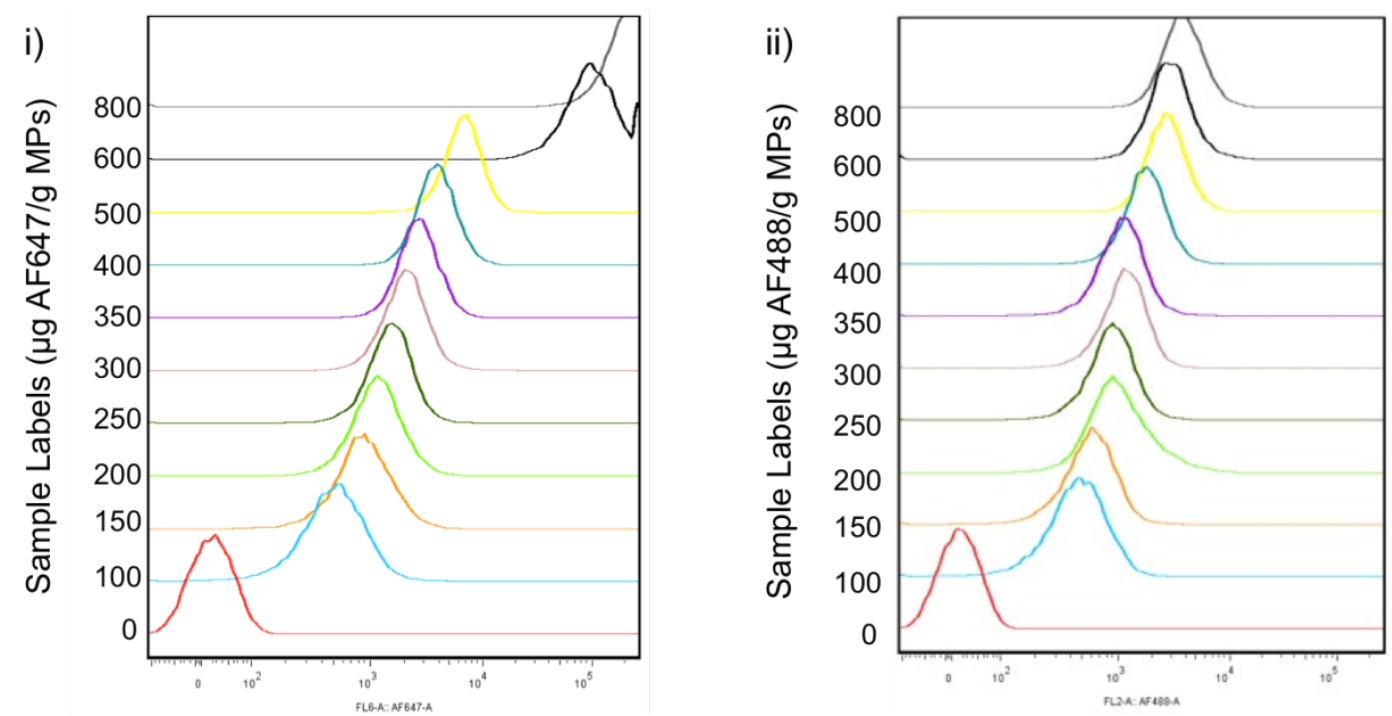

Figure S1. Detection of fluorescence of microparticles by flow cytometry with varying amounts of incorporated i) AF647 and ii) AF488 dye. 
Table 1. Quantification of functionalizable amine groups, as per the section in the experimental section of the main text, entitled, Surface functionalization of microparticles with APTMS.

\begin{tabular}{|l|l|l|}
\hline $\begin{array}{l}\text { Time (refers to length of time the } \\
\text { microparticles are stirred/in } \\
\text { contact with APTMS) }\end{array}$ & $\begin{array}{l}\text { Fmoc assay result }\left(\mu \mathrm{mol}-\mathrm{NH}_{2}\right. \\
\text { groups } / 100 \mathrm{mg} \text { of microparticles) }\end{array}$ & $\begin{array}{l}\text { Calculated number of chemically } \\
\text { accessible }-\mathrm{NH}_{2} / \mathrm{nm}^{2}\end{array}$ \\
\hline 0 & -0.01 & 0 \\
\hline $1 \mathrm{~min}$ & 0.11 & 0.24 \\
\hline $4 \mathrm{~h}$ & 0.57 & 1.26 \\
\hline $8 \mathrm{~h}$ & 0.59 & 1.30 \\
\hline $12 \mathrm{~h}$ & 0.61 & 1.35 \\
\hline $24 \mathrm{~h}$ & 0.70 & 1.54 \\
\hline
\end{tabular}

Description of the calculations: The Fmoc assay result refers to $\mu \mathrm{mol} / 100 \mathrm{mg}$ of microparticles following deprotection of the FmocGly with $30 \%$ piperidine in acetonitrile. If the value in the second column is 1.0 , then it means for $100 \mathrm{mg}$ of microparticles, $1 \mu \mathrm{mol}$ of $\mathrm{NH}_{2}$ groups were functionalized. For the calculations to provide the data in the third column, the following calculation was performed:

-Molecular mass of silica $=60.1 \mathrm{~g} / \mathrm{mol}$

-Density of amorphous silica $=2.116 \mathrm{~g} / \mathrm{cm}^{-3}$

-Area of a single microparticle $=4 \pi r^{2}=4 \pi(500 \mathrm{~nm})^{2}$, assuming an average diameter of 1 $\mu \mathrm{m}=3.14159 \times 10^{6} \mathrm{~nm}^{2}$

-Volume of a single microparticle $=4 / 3 \pi \mathrm{r}^{3}=4 \pi(500 \mathrm{~nm})^{3}=5.236 \times 10^{8} \mathrm{~nm}^{3}$

-Volume of $100 \mathrm{mg}$ of amorphous silica $=4.726 \times 10^{-2} \mathrm{~cm}^{3}$

-Total number of microparticles in $100 \mathrm{mg}=4.726 \times 10^{-2} \mathrm{~cm}^{3} / 5.236 \times 10^{8} \mathrm{~nm}^{3}=9.026 \mathrm{x}$ $10^{10}$ microparticles

-Total surface area of $9.026 \times 10^{10}$ microparticles $(=100 \mathrm{mg})=2.84 \times 10^{17} \mathrm{~nm}^{2}$

-Therefore, based on the results of column 2, as an example, $0.50 \mu \mathrm{mol}$ of $-\mathrm{NH}_{2}$ groups $=$ $\sim 3 \times 10^{17}$

-Number $-\mathrm{NH}_{2}$ groups $/ \mathrm{nm}^{2}=1.0$

Every sample was subjected to this protocol, and if the number of $-\mathrm{NH}_{2}$ groups $/ \mathrm{nm}^{2}<$ 1.0 , the sample was discarded. 


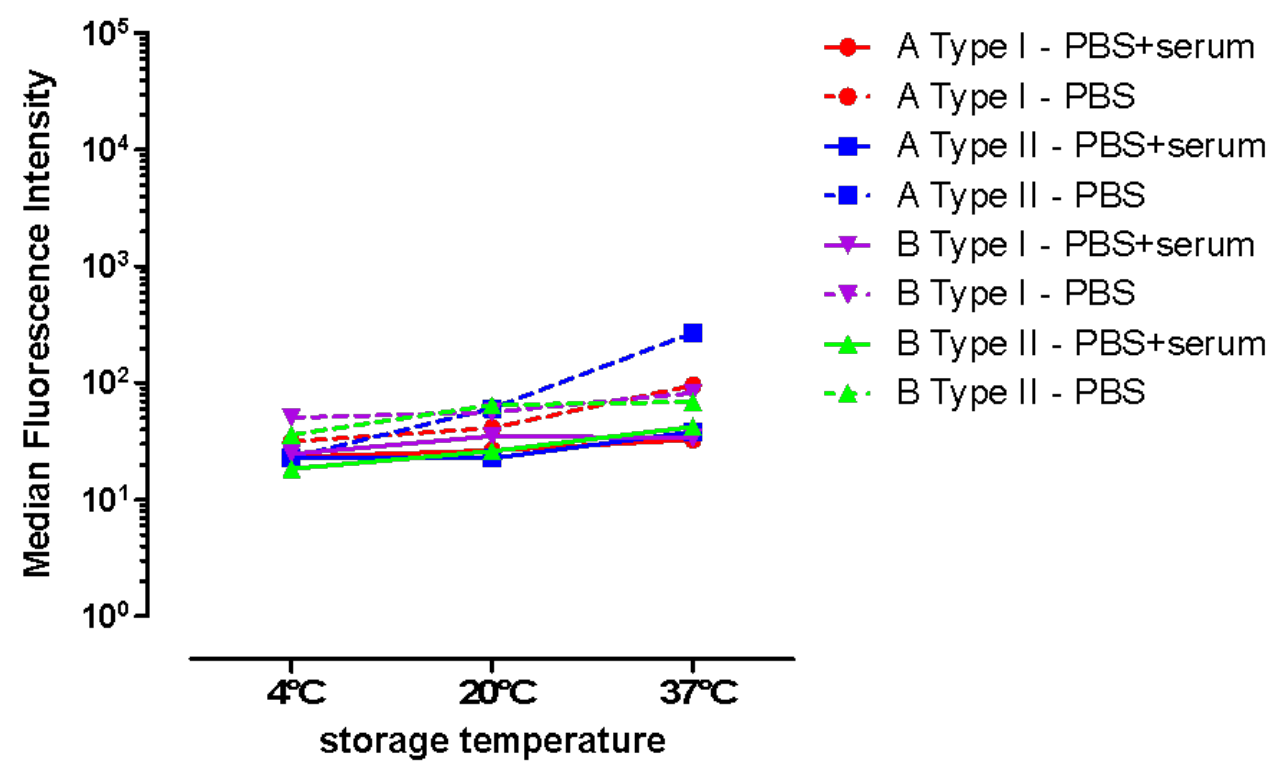

Figure S2. Detection of non-specific antibody binding to antigen-functionalized microparticles. After storage for 7 days at $4^{\circ} \mathrm{C}, 20^{\circ} \mathrm{C}$ and $37^{\circ} \mathrm{C}$, antigen functionalized microparticles were incubated with mismatched antibodies to detect non-specific interactions. A-antigen-functionalized microparticles were incubated with anti-B antibodies; and, B-antigen-functionalized microparticles with anti A antibodies in PBS alone (dotted line) or in PBS supplemented with serum as blocking buffer (solid line). Goat anti-mouse IgM-PE was used as secondary antibody. The median fluorescence intensity (MFI) represents non-specific binding of the antibodies to A type I (red), A type II (blue), B type I (purple) and B type II (green) functionalized microparticles that were stored at the various temperatures. 

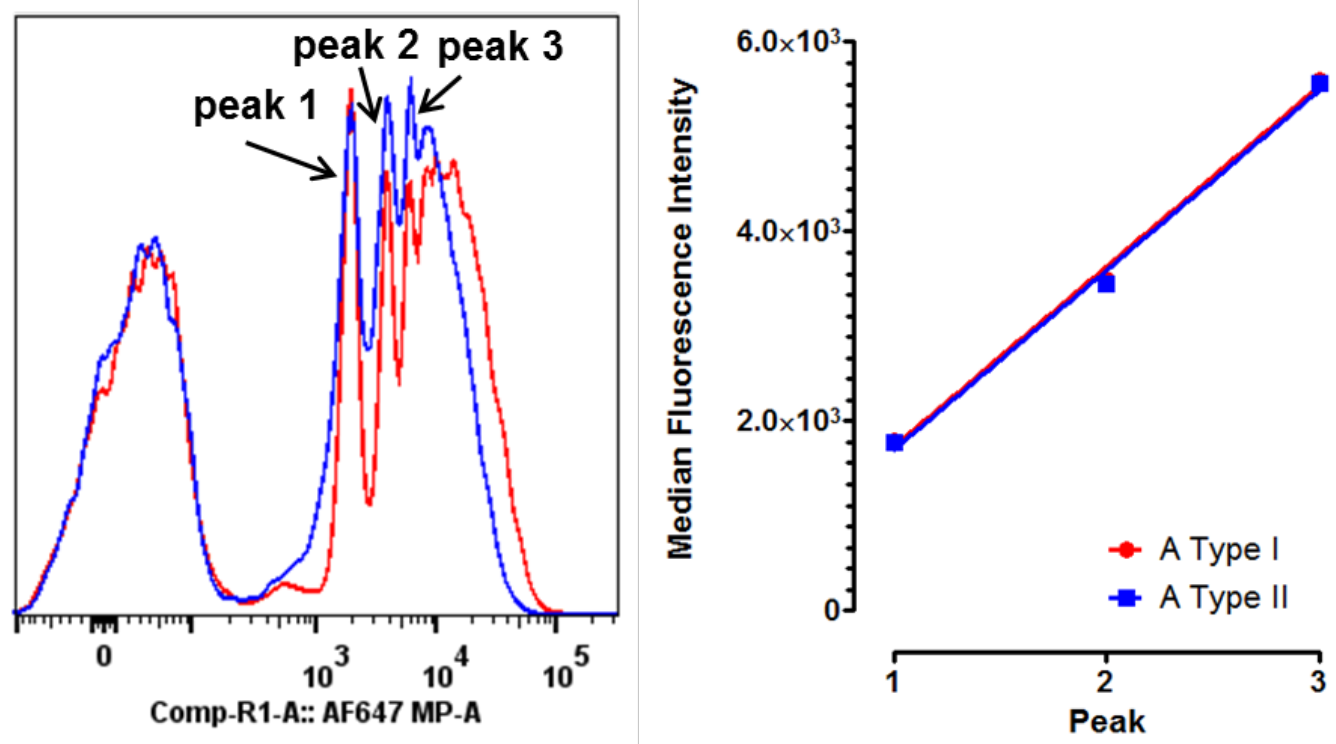

Figure S3. Analysis of peak MFIs of cells bound to A-antigen-functionalized microparticles. The MFI of the first three peaks within the cell population that bound to A type I (red) or A type II (blue) antigen-functionalized microparticles is plotted. A linear increase in MFI was observed with each peak. 


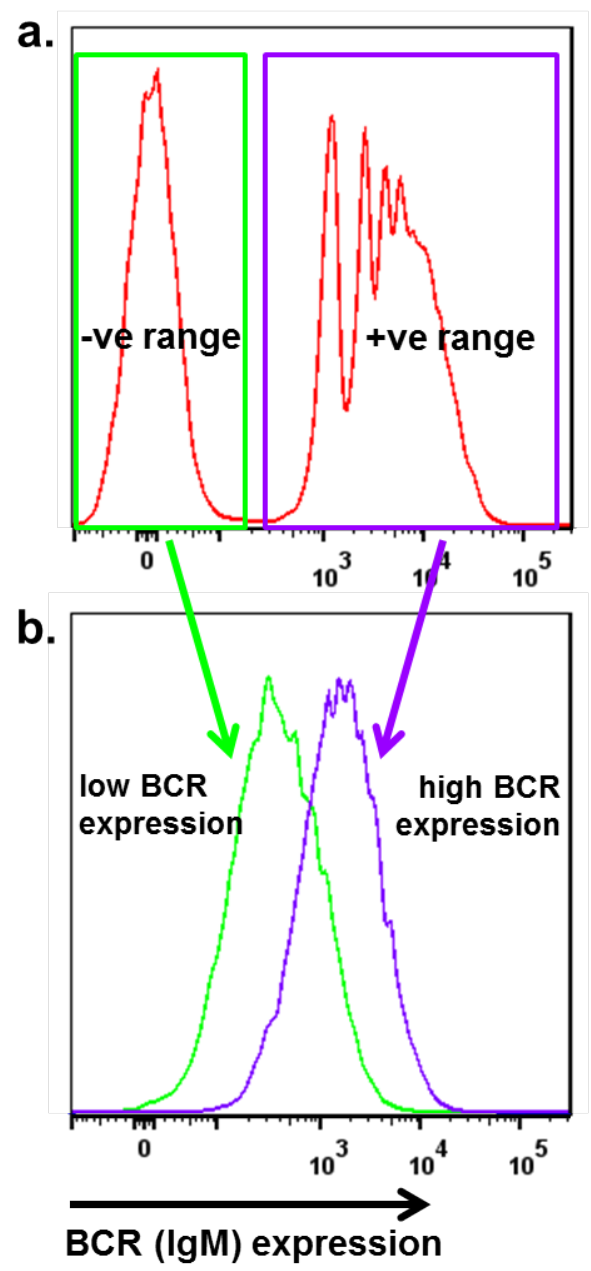

Figure S4. Cells bound to A-antigen-functionalized microparticles have a high level of $B$ cell receptor (BCR) expression. a) BCR expression was analyzed of A-antigenspecific B cells that bound to A type I microparticles (+ve range; purple gate) in comparison to unbound cells (-ve range; green gate). b) Cells that bind to the microparticles (purple histogram) had a higher BCR expression than unbound cells (green histogram). 